\title{
Factors Related to Physical Strength of Banana Pseudostem
}

\author{
Shenghe Chang ${ }^{1,2 *}$, Zhengjing $\mathrm{Wu}^{3 *}$, Wei Sun ${ }^{1,2}$, Lan Qiao ${ }^{3}$, Qi Zeng33, Jingyi Zhang3, Haiyan Shu ${ }^{1,2 \#}$ \\ ${ }^{1}$ Haikou Experimental Station, Chinese Academy of Tropical Agricultural Sciences, Haikou, China \\ ${ }^{2}$ The Key Lab of Hainan Banana Genetics and Breeding, Haikou, China \\ ${ }^{3}$ School of Forestry, Henan University of Science and Technology, Luoyang, China \\ Email: "shuhy@zzu.edu.cn
}

How to cite this paper: Chang, S.H., Wu, Z.J., Sun, W., Qiao, L., Zeng, Q., Zhang, J.Y. and Shu, H.Y. (2018) Factors Related to Physical Strength of Banana Pseudostem. Advances in Bioscience and Biotechnology, 9, 136-146.

https://doi.org/10.4236/abb.2018.94011

Received: February 26, 2018

Accepted: April 23, 2018

Published: April 26, 2018

Copyright (c) 2018 by authors and Scientific Research Publishing Inc. This work is licensed under the Creative Commons Attribution International License (CC BY 4.0).

http://creativecommons.org/licenses/by/4.0/

\begin{abstract}
Banana is an important fruit in China. Banana production played important role in economic development in tropical region. Banana production in China was always cut because of lodging caused by typhoon. Getting new cultivars with high resistance to lodging is the basic resolution to resolve this problem. Screening and identifying the germ plasm resource is the first step to breed new cultivars. Banana plant height was high. A single banana plant needs large area. It is difficult to screen the germ plasm resource by identifying the physical strength of banana pseudostem. This research focused on studying the relationship between pseudostem and plant height, pseudostem diameter, acid soluble lignin, acid insoluble lignin, total lignin, pore numbers of pseudostem cross section, and the expression of 4-coumarate:CoA ligase (4CL). Results showed that the plant with high physical strength in seedling stage always has high physical strength in mature stage. The physical strength of banana seedling pseudostem was closely related to pseudostem diameter and total lignin. Pseudostem diameter and total lignin can be used to predict the physical strength of mature banana pseudostem. Work on identifying and screening the physical strength of banana germ plasm pseudostem can be reduced by measuring seedling pseudostem diameter and total lignin in pseudostem of banana germplasm.
\end{abstract}

\section{Keywords}

Banana, Germ Plasm Resource, Lodging, Physical Strength of Pseudostem

\section{Introduction}

Banana is an important fruit with large production in world [1]. It has the largest

*Equal contributor.

\#Corresponding author. 
trade volume among the fruits. Banana is also an important crop in many developing countries [2]. It is the main crop for about four hundred million people. United Nations ranked banana as the fourth crop following rice, wheat and maize [3]. Culturing banana not only can help developing countries cope with food crisis, it can also improve the status of the countries in world.

China is a country with high production of banana [4]. Chinese bananas were planted mainly in Guangdong, Hainan, Guangxi, Fujian, Yunnan and Taiwan [5]. These provinces belonged to monsoon climate area. Typhoon always passed through these provinces. Chinese banana production has always been heavily affected by typhoon [6]. Cultivating new banana cultivars with high physical strength to lodging is the basic resolution to resolve this problem [5]. Identifying and screening the germplam resource is the first step to cultivate new cultivars. Mature banana plant has high height and the single plant needs large space. On average, an acre space can only accommodate 780 to 1080 banana plants. Getting a valuable single plant always needs to screen thousands of plants. Cultivating new cultivars with high strength by screen mature banana plants needs much hard work. If the physical strength of pseudostem of mature banana can be predicted in seedling stage, much labor and work can be saved. The breeding time can also be reduced.

Plant's lodging-resistance was controlled by many genes [7] [8]. Plant's lodging-resistance was closely related with plant height [9]-[15]. Many crops' lodging resistances were improved by selecting dwarf mutants [9]-[15]. Some researchers found that plants' lodging-resistances were positively correlated with stem's diameter [16]. After a wheat double haploid line was gotten by hybridizing the line CA9613 and H1488, the physical strength of the stem and the characters of the basic stem were measured at milk stage [17]. Six QTLs are responsible for physical strength of stem, thickness of stem wall, pore diameter and stem diameter were found in $1 \mathrm{~A}, 2 \mathrm{D}, 3 \mathrm{~A}$, and $3 \mathrm{~B}$ [17]. This suggested that the physical strength may have relationship with pore numbers. The physical strength of the plant stem was finally determined by the carbohydrates in the stem [18]. Plant stem was made mainly of lignin and cellulose [18]. Cellulose was essentially a soft net structure. The physical strength of plant stem was mainly determined by lignin content [19] [20]. A little decrease of lignin content in stem can cause the remarkable decline in physical strength of plant stem [21]. A little increase of lignin content in stem may cause the physical strength of plant stem rise significantly [18]. Plant's lignin-synthesis was also controlled by many genes. Among these genes, 4-coumarate:CoA ligase (4CL) genes located at the entrance to the pathway of lignin synthesis [5]. The expression of 4CL was closely correlated with plant's lodging-resistance [22] [23] [24] [25] [26].

This research was mainly focused on studying the relationship between pseudostem and plant height, pseudostem diameter, acid soluble lignin, acid insoluble lignin, total lignin, pore numbers of pseudostem cross section, and the expression of 4-coumarate:CoA ligase (4CL). Characters closely related to physical strength of pseudostem were to be found. 


\section{Materials and Methods}

\subsection{Materials}

Eight banana cultivars were used in this research, they are Apple (ABB, N/A, Hawaii, Dessert), Fenjiao ABB, Saba, China, Dessert), Baxijiao (AAA, Cavendish, Australia, Dessert), Musa balbisiana (balbisiana, N/A, China, N/A), Musa acuminate (acuminata, Burmannica, Myanmar, N/A), King (AA, Inarnibal, Philippines, Dessert), Hongxiangjiao (AAA, Red, China, Dessert), and Yunnandajiao (AAB, N/A, China, Dessert), respectively. Tissue culture seedlings were planted in pots containing potting soil for two months. Pseudostem physical strength, seedling plant height, pseudostem diameter, acid soluble lignin, acid insoluble lignin, total lignin, pore numbers of pseudostem cross section, and the expression of 4-coumarate:CoA ligase (4CL) were measured. For every cultivar, 20 plants were cultured in land. Before male fluorescence appeared, the physical strength of the mature stage and the plant height of mature stage were measured.

\subsection{Relative-Quantitative Polymerase Chain Reaction (RQRT-PCR)}

Banana strains were cultured in bottle using tissue culture for one month. And then, the seedlings were transferred to pots containing potting soil and cultured for two months. The first-strand cDNA samples were synthesized using $200 \mathrm{ng}$ total RNA from all pseudostems of banana seedlings, respectively. RQRT-PCR was done for Mu4CL15 using the specific primers P1

(5'-ATGGAGTCATACTCGATGCCGGAG-3') and P2(5'-TCAAGCGGATGGAAACTGGCTTC-3'). PCR reaction was carried out for 30 cycles $\left(94^{\circ} \mathrm{C} 30 \mathrm{~s}, 63^{\circ} \mathrm{C} 60 \mathrm{~s}, 72^{\circ} \mathrm{C} 90 \mathrm{~s}\right)$. As a control, RT-PCR was performed using two primers (P5: 5'-CCTGCTCTCTACATTTACAT-3' and P6: 5'-CCTTCATCGCCTTCATCACC-3') specific for the wheat tublin geneMutubulin. PCR was performed for 30 cycles $\left(94^{\circ} \mathrm{C} 30 \mathrm{~s}, 50^{\circ} \mathrm{C} 60 \mathrm{~s}, 72^{\circ} \mathrm{C} 120 \mathrm{~s}\right)$. PCR results were analyzed using $1.0 \%$ agarose gel electrophoresis. For every reaction, four repetitions were performed.

\subsection{Measurement of Pseudostem Physical Strength}

Physical strength of banana pseudostem was measured according to the published [1] [6]. After banana seedlings were grown in pots, stem physical strength apparatus (YYD-IA, Top Apparatus, Beijing, China) was put in the middle of banana seedling pseudostem vertically. Push the apparatus until the angle between the pseudostem and the ground reach to 45 degree. The datum on the screen shown was the pseudostem physical strength measured. For mature banana plant, portable electronic scale was used. The steelyard hook was fixed in the upper pseudostem. The scale was pulled until the angle between the pseudostem and the ground was 45 degree. The datum shown in the screen (D1) was transformed into the final data (D2) according to the following formula, D2 = 
$\mathrm{D} 1^{\star} 9.8$. For every treatment, six plants were measured and the average value was used.

\subsection{Determination of Acid Soluble Lignin (ASL) and Acid Insoluble Lignin (AIL)}

Acid soluble lignin (ASL) and acid insoluble lignin (AIL) in banana pseudostem were mainly according to the published paper [27]. Middle part of the pseudostem was collected as sample. The samples were freeze-dried and then, they were ground into fine powder using liquid nitrogen. $3.00+0.01 \mathrm{~g}$ sample were put in Soxhelt's and treated with ethanol for 24 hours. After the powder was air-dried, it was put in test tube. $3 \mathrm{ml}$ of $72 \%$ sulphuric acid was added and vortexed for one minute. The tubes were put in $30^{\circ} \mathrm{C}$ water bath for one hour, votex every five minutes. $84 \mathrm{ml}$ of distilled water was added and the sulphuric acid was adijusted to $4 \%$. The test tubes were put in $121^{\circ} \mathrm{C}$ for 1 hour and then, the mixture was filtered using filter paper. The filtrate was collected and A320 nm was measured, using 4\% sulphuric acid as control. ASL(\%) $=$ A320 $\mathrm{nm} \times 86.73 \times \mathrm{n} /(30 \times$ $\mathrm{W}) \times 100 \%$. $\mathrm{N}$ was the dilution factor. $\mathrm{W}$ was the dry weight of the sample. 30 represented the extinction coefficient. Pot was kept in $575^{\circ} \mathrm{C}+25^{\circ} \mathrm{C}$ in muffle furnace for 6 hours. The sample was cooled to room temperature and weighed. The value was named as W1. The filter paper was dried in $105^{\circ} \mathrm{C}$ for 6 hours. And then, it was cooled to room temperature and weighed. The value was named as W2. A single filter paper was dried in $105^{\circ} \mathrm{C}$ for 6 hours. It was cooled to room temperature and weighed. The value was named as $\mathrm{W} 3.50 \mathrm{ml}$ of distilled water was used to wash the residue. Filter paper and residue were both put in pot and dried in $105^{\circ} \mathrm{C}$ for 4 hours. They were cooled and weighed. The value was named as $\mathrm{W} 4$. And then, the pot containing filter paper and residue was put in muffle furnace in $575^{\circ} \mathrm{C}+25^{\circ} \mathrm{C}$ for 24 hours. They were cooled to room temperature and weighed. The value was named as W5.

$\mathrm{AIL}=(\mathrm{W} 4-\mathrm{W} 5-\mathrm{W} 3 \times \mathrm{W} 2 / \mathrm{W} 1) / \mathrm{W} \times 100 \%$. For every treatment, four repetitions were performed and the average value was used.

\section{Results and Discussion}

\subsection{The Physical Strength of Pseudostem Has No Relationship with Plant Height}

Lodging always happened to crops before harvest [28] [29] [30] [31]. The grain production and quality often decreased heavily because of lodging [32] [33] [34]. The weakness of stem or buttress root, insect, or pathogen all can lead crops to fall down [35]. Too much fertilization can make crops lodge too [36] [37]. The lodging of crops was closely related with plant height. The plant was higher, the center of gravity of the plant was higher and the lodging happened easier. Dwarf breeding always the important work for breeders on wheat, maize and rice [9]-[15]. However, after the physical strength of banana seedling pseudostem and plant height of eight banana cultivars were analyzed, it was found that the 
relationship between the physical strength of seedling pseudostem and plant height was not significant (Table 1). For example, after Apple banana seedlings were cultured in pot for two months, the plant height was $27 \mathrm{~cm}$. the physical strength of pseudostem was $8.6 \mathrm{~N}$. The corresponding values of Baxijiao were 30 $\mathrm{cm}$ and $8.9 \mathrm{~N}$. The corresponding values of Fenjiao were $33 \mathrm{~cm}$ and $8.7 \mathrm{~N}$. The seedling of Fenjiao was higher than Apple banana. The physical strength of Fenjiao was also stronger than that of Apple banana. The seedling of Fenjiao was higher than Baxijiao. However, the physical strength of Fenjiao was less than that of Baxijiao. These demonstrated that the physical strength of banana seedlings has necessary connection with plant height. Plant height cannot be selected as a target for screening new cultivars with high resistance to lodging.

\subsection{The Pseudostem Diameter Can Be Used as an Indicator for Screening New Cultivars with High Resistance to Lodging}

After the pseudostem diameters of the seedlings were measured, it was found that Yunnandajiao has the largest pseudostem diameter. The second was Hongxiangjiao. And then, Baxijiao, Fenjiao, Apple, King, Musa balbisiana, Musa acuminate, from the largest to the least (Table 2). This order was completely consistent with that of the physical strength of seedling pseudostem (Table 1). These results indicated that if the banana cultivar has large pseudostem diameter, it has high possibility to have strong physical strength of pseudostem. The physical strength of seedling pseudostem has close relationship with pseudostem diameter. Using seedling pseudostem diameter as target to screen banana germplam resource, it has high possibility to get new cultivar with strong resistance to lodging. Ishimaru et al. (2008) also found that the determined factor for rice lodging resistance was the resistance strength of the basic stem, not the plant height [38]. Mulder (1954) also found that the lodging resistance of plant was mainly determined by the weight of the plant upper part and the resistance strength of the basic part [39].

Table 1. Seedling plant height (SPH), seedling plant physical strength (SPPH) and mature plant physical strength (MPPS).

\begin{tabular}{cccc}
\hline Strains & MPPS $(\mathrm{N})$ & SPPS $(\mathrm{N})$ & SPH $(\mathrm{cm})$ \\
\hline Apple & $1337 \pm 51$ & $8.6 \pm 0.1$ & $27 \pm 1$ \\
Fenjiao & $1433 \pm 50$ & $8.7 \pm 0.1$ & $33 \pm 1$ \\
Baxijiao & $1568 \pm 78$ & $8.9 \pm 0.1$ & $30 \pm 1$ \\
Musa acuminate & $1056 \pm 32$ & $8.2 \pm 0.1$ & $26 \pm 1$ \\
Musa balbisiana & $1123 \pm 20$ & $8.3 \pm 0.1$ & $27 \pm 2$ \\
King & $1250 \pm 27$ & $8.5 \pm 0.1$ & $28 \pm 1$ \\
Hongxiangjiao & $1891 \pm 98$ & $9.2 \pm 0.2$ & $34 \pm 2$ \\
Yunnandajiao & $2165 \pm 101$ & $9.7 \pm 0.2$ & $35 \pm 3$ \\
\hline
\end{tabular}


Table 2. Seedling pseudostem diameter and pore number of seedling pseudostem cross section.

\begin{tabular}{ccc}
\hline Strains & $\begin{array}{c}\text { Seedling pseudostem } \\
\text { diameter }(\mathrm{cm})\end{array}$ & $\begin{array}{c}\text { Seedling pseudostem cross } \\
\text { section pore number }\end{array}$ \\
\hline Apple & $0.9 \pm 0.1$ & $36 \pm 5$ \\
Fenjiao & $1.1 \pm 0.1$ & $45 \pm 8$ \\
Baxijiao & $1.2 \pm 0.1$ & $45 \pm 12$ \\
Musa acuminate & $0.7 \pm 0.1$ & $37 \pm 4$ \\
Musa balbisiana & $0.7 \pm 0.1$ & $38 \pm 7$ \\
King & $0.8 \pm 0.1$ & $40 \pm 4$ \\
Hongxiangjiao & $1.8 \pm 0.1$ & $42 \pm 6$ \\
Yunnandajiao & $2.0 \pm 0.2$ & $53 \pm 11$ \\
\hline
\end{tabular}

\subsection{The Relationship between Pore Number and Physical Strength of Seedling Pseudostem Was Not Significant}

Results showed that the pore numbers of the seedling pseudostem has no relationship with the physical strength of the pseudostem. For example, the pseudostem of Baxijiao was stronger than that of Musa balbisiana. The pseudostem cross section of Baxijiao also has more pore number than that of Musa balbisiana. At the same time, the pseudostem of Baxijiao was weaker than that of Hongxiangjiao. The pseudostem cross section of Baxijiao still has more pore number than that of Hongxiangjiao. These showed that the relationship between the pore number of pseudostem cross section and the physical strength of seedling pseudostem was not significant. The pore number of pseudostem cross section cannot be used as a target to screen new banana cultivars with high resistance to lodging.

\subsection{The Physical Strength of Pseudostem Increased with Lignin Content}

As shown in Table 1 and Table 3, the pseudostem of Yunnandajiao and Baxijiao have the most ASL. The value was $2.5 \%$. The ASL values of the pseudostem of Hongxiangjiao, King and Fenjiao were very similar. The ASL value of Musa balbisiana was the least. The relationship between ASL and physical strength of pseudostem was not significant (Table 1, Table 3). The order of the AIL of pseudostem of the banana seedlings was Yunnandajiao, Hongxiangjiao, Baxijiao, Fenjiao, King, Musa acuminate, Musa balbisiana, Apple, from the most to the least (Table 3). The physical strength of pseudostem has no remarkable relationship with AIL (Table 1, Table 3). The order of the total lignin content in different banana cultivars was Yunandajiao, Hongxaingjiao, Baxijiao, Fenjiao, Musa acuminate, King, Musa balbisiana, Apple (Table 3). This order was completely consistent with that of the physical strength of pseudostem (Table 1, Table 3). These demonstrated that although neither ASL nor AIL can be used as basis to predict the physical strength of pseudostem of the banana germplasm, 
Table 3. Acid soluble lignin (ASL), acid insoluble lignin (AIL) and total lignin (TL) in seedling pseudostem.

\begin{tabular}{cccc}
\hline Strains & ASL $(\%)$ & AIL $(\%)$ & TL $(\%)$ \\
\hline Apple & $1.7 \pm 0.1$ & $9.0 \pm 0.1$ & $10.7 \pm 0.1$ \\
Fenjiao & $2.0 \pm 0.1$ & $11.2 \pm 0.1$ & $13.2 \pm 0.1$ \\
Baxijiao & $2.5 \pm 0.1$ & $11.8 \pm 0.1$ & $14.3 \pm 0.1$ \\
Musa acuminate & $1.7 \pm 0.1$ & $11.0 \pm 0.1$ & $12.7 \pm 0.1$ \\
Musa balbisiana & $1.5 \pm 0.1$ & $9.6 \pm 0.1$ & $11.1 \pm 0.1$ \\
King & $2.0 \pm 0.1$ & $10.5 \pm 0.1$ & $12.5 \pm 0.1$ \\
Hongxiangjiao & $2.0 \pm 0.2$ & $13.2 \pm 0.2$ & $15.2 \pm 0.2$ \\
Yunnandajiao & $2.5 \pm 0.3$ & $13.7 \pm 0.3$ & $16.2 \pm 0.3$ \\
\hline
\end{tabular}

the total lignin content in pseudostem can be used to predict the physical strength of the plant.

\subsection{The Expression of the Gene Mu4CL15 Was Close Related to the Physical Strength of the Seedling Pseudostem}

As the metabolism catalyzed by 4-coumarate:CoA ligase located at the entrance of lignin anabolism in plant, the metabolism catalyzed by 4-coumarate:CoA ligase maight be the rate-limiting step for lignin anabolism in plant. The expression of 4-coumarate:CoA ligase gene may have close relationship with the physical strength of banana pseudostem. 4-coumarate:CoA ligase always existed as family in plant genome. There were 25 4-coumarate:CoA ligase genes in banana A genome. Results showed that the order of the amplified products of Mu4CL15 was consistent with that of physical strength of pseudostem (Table 1, Figure 1). The banana seedlings with high expression of 4-coumarate:CoA ligase gene Mu4CL15 always have strong pseudostem. This suggested that the physical strength of the pseudostem of the banana plants can be predicted by measuring the expression of Mu4CL15 in pseudostem.

\subsection{The Plant with High Physical Strength at Seedling Stage Always Has High Resistance to Lodging at Mature Stage}

For every cultivar, five seedlings with high physical strength and five seedlings with weak physical strength were selected and grown in field. At mature stage, the physical strength of the plants was measured. Results showed that under the same manage condition, the physical strength of the plants at mature stage was proportionate to that of the plants at seedling stage (Table 1). The plant with high physical strength at seedling stage always has high resistance to lodging at mature stage (Table 1). This suggested that the physical strength of the pseudostem of the banana plants at mature stage can be predicted by measuring the physical strength of the plants at seedling stage. 


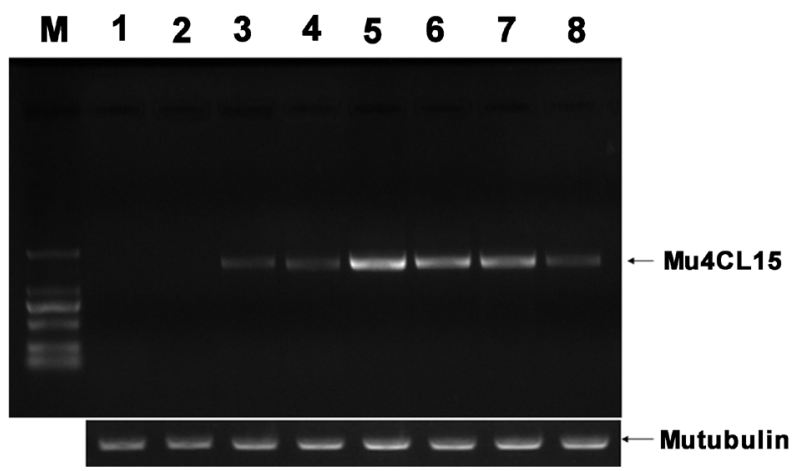

Figure 1. The expression of Mu4CL15 in seedling pseudostemof different cultivars M was DNA marker (D2000) (Tiangen Biotech, Beijing, China) 1, 2, 3, 4, 5, 6, 7, 8 was Apple, Musa balbisiana, King, Fenjiao, Yunnandajiao, Hongxiangjiao, Baxijiao, Musa acuminate, respectively.

\section{Conclusion}

The relationship between plant height and physical strength of banana pseudostem was not significant. The pseudostem diameter becomes larger, the pseudostem has stronger physical strength. The pore number of the pseudostem cross section has no relationship with the physical strength of the seedling pseudostem. Although neither the order of ASL nor that of AIL was consistent with that of the physical strength of the banana pseudostem, the order of total lignin content in pseudostem was completely consistent with that of the physical strength of the banana pseudostem. The total lignin content in pseudostem can be used to predict the physical strength of the plant. The physical strength of the pseudostem of the banana plants at mature stage can be predicted by measuring the physical strength of the plants at seedling stage in seedling pseudostem. Banana lodging-resistant breeding might be accelerated by measuring the physical strength of the plants at seedling stage.

\section{Acknowledgements}

This work was supported by the Key Research and Developmental Plan Item of Hainan Province (No. ZDYF2017024).

\section{References}

[1] Shu, H., Sun, W., Wei, Q., Wang, Z., Yin, M., Han, Q., Jin, Z., Li, J. and Chang, S. (2017) Functional Identification of Mu4CL15 Gene in Banana. Genomics and Applied Biology, 36, 3025-3033.

[2] Heslop-Harisson, J.S. (2011) Genomics, Banana Breeding and Super Domestication. In: Jiang, Z., Yi, G., Molina, A. and Bergh, I., Eds., Proceeding of the International ISHS-ProMusa Symposium Global Perspectives on Asian Challenges, Guangzhou, 14-18 September 2001, 55-62.

[3] Gewolb, J. (2001) DNA Sequencers to go Banana's? Science, 293, 585-586. https://doi.org/10.1126/science.293.5530.585a

[4] Li, C.Y., Wei, Y.R., Wu, Y.L., Huang, B.Z. and Yi, G.J. (2011) Status, Challenges and 
Trends of Chinese Banana Industry. In: Jiang, Z., Yi, G., Molina, A. and Bergh, I., Eds., Proceeding of the International ISHS-ProMusa Symposium Global Perspectives on Asian Challenges, 14-18 September 2001, Guangzhou, 31-36. https://doi.org/10.17660/ActaHortic.2011.897.1

[5] Shu, H., Sun, W., Wang, Z., Yin, M., Han, Q., Zhou, Z., Dai, M., Jin, Z., Li, J. and Chang, S. (2016) The Possible Analysis for Breeding Banana Varieties with High Resistance to Typhoon. Molecular Plant Breeding, 14, 1-11.

[6] Chang, S., Sun, W., Xu, G., Wei, Q., Li, J. and Shu, H. (2017) Enhancing Lodging Resistance of Banana Plant by Transforming 4-coumarate:CoA ligase Gene Mu4CL15. Molecular Plant Breeding, 15, 1-11.

[7] Keller, C., Karutz, C., Schmid, J.E., Stamp, P., Winzeler, M., Keller, B. and Messmer M. (1999) Quantitative Trait Loci for Lodging Resistance in a Segregating Wheat $\mathrm{x}$ Spelt Population. Theoretical and Applied Genetics, 98, 1171-1182. https://doi.org/10.1007/s001220051182

[8] Berry, P.M., Sterling, M., Spink, J.H., Baker, C.J., Sylvester-Bradley, R., Mooney, S.J., Tams, A.R. and Ennos A.R. (2004) Understanding and Reducing Lodging in Cereals. Advances in Agronomy, 84, 217-271.

https://doi.org/10.1016/S0065-2113(04)84005-7

[9] Garthwaite, D.G., Thomas, M.R., Anderson, H. and Stoddart, H. (2005) Pesticide Usage Survey Report 202. Arable Crops in Great Britain 2004. Department for the Environment Food and Rural Affairs, London.

[10] Flintham, J.E., Borner, A., Worland, A.J. and Gale, M.D. (1997) Optimizing Wheat Grain Yield: Effects of Rht (Gibberellin-Insensitive) Dwarfing Genes. Journal of Agricultural Science, 128, 11-25. https://doi.org/10.1017/S0021859696003942

[11] Kertesz, Z., Flintham, J.E. and Gale, M.D. (1991) Effects of Rht Dwarfing Genes on Wheat Grain Yield and Its Components under Eastern European Conditions. Cereal Research Communications, 19, 297-304.

[12] Miralles, D.J. and Slafer, G.A. (1995) Individual Grain Weight Responses to Genetic Reductions in Culm Length in Wheat as Affected by Source-Sink Manipulations. Field Crops Research, 43, 55-66. https://doi.org/10.1016/0378-4290(95)00041-N

[13] Baylan, H.S. and Singh, O. (1994) Pleiotropic Effects of GAinsensitiveRht Genes on Grain Yield and Its Component Characters in Wheat. Cereal Research Communications, 22, 195-200.

[14] Allan, R.E. (1986) Agronomic Comparisons among Wheat Lines Nearly Isogenic for Three Reduced Height Genes. Crop Science, 26, 707-710. https://doi.org/10.2135/cropsci1986.0011183X002600040014x

[15] Richards, R.A. (1992) The Effect of Dwarfing Genes in Spring Wheat in Dry Environments. I. Agronomic Characteristics. Australian Journal of Agricultural Research, 43, 517-527. https://doi.org/10.1071/AR9920517

[16] Yang, Y., Zhu, Z., Zhang, Y., Chen, T., Zhao, Q., Zhou, L., Yao, Z., Zhang, Y., Dong, S. and Wang, C. (2011) Relationship between Lodging Resistance and Stem Morphological Traits in Different Rice Varieties (Lines). Jiangsu Journal of Agricultural Sciences, 27, 231-235.

[17] Hai, L., Guo, H.J., Xiao, S.H., Jiang, G.L., Zhang, X.Y., Yan, C.S., Xin, Z.Y. and Jia, J.Z. (2005) Quantitative Trait Loci (QTL) of Stem Strength and Related Traits in a Doubled-Haploid Population of Wheat (Triticumaestivum L.). Euphytica, 141, 1-9. https://doi.org/10.1007/s10681-005-4713-2

[18] Ma, Q.H. (2009) The Expression of Caffeic Acid 3-O-methyltransferase in Two 
Wheat Genotypes Differing in Lodging Resistance. Journal of Experimental Botany, 60, 2763-2771. https://doi.org/10.1093/jxb/erp132

[19] Jones, L., Ennos, A.R. and Turner, S.R. (2001) Cloning and Characterization of Irregular xylem4 (irx4): A Severely Lignin-Deficient Mutant of Arabidopsis. The Plant Journal, 26, 205-216. https://doi.org/10.1046/j.1365-313x.2001.01021.x

[20] Ma, Q.H., Xu, Y., Lin, Z.B. and He, P. (2002) Cloning of cDNA Encoding COMT from Wheat Which Is Differentially Expressed in Lodging-Sensitive and -Resistant Cultivars. Journal of Experimental Botany, 53, 2281-2282. https://doi.org/10.1093/jxb/erf102

[21] Halpin, C., Holt, K., Chojecki, J., Oliver, D., Chabbert, B., Monties, B., Edwards, K., Barakats, A.A. and Foxon, G.A. (1998) Brown-Midrib Maize (bm1): A Mutation Affecting the Cinnamyl Alcohol Dehydrogenase Gene. The Plant Journal, 14, 545-553. https://doi.org/10.1046/j.1365-313X.1998.00153.x

[22] Saballos, A., Sattler, S.E., Sanchez, E., Foster, T.P., Xin, Z., Kang, C., Pedersen, J.F. and Vermerris, W. (2012) Brown midrib2 (Bmr2) Encodes the Major 4-coumarate: Coenzyme A Ligase Involved in Lignin Biosynthesis in Sorghum (Sorghum bicolor (L.) Moench). Plant Journal, 70, 818-830. https://doi.org/10.1111/j.1365-313X.2012.04933.x

[23] Wagner, A., Donaldson, L., Kim, H., Phillips, L., Flint, H., Steward, D., Torr, K., Koch, G., Schmitt, U. and Ralph, J. (2009) Suppression of 4-coumarate-coA Ligase in the Coniferous Gymnosperm Pinusradiate. Plant Physiology, 149, 370-383. https://doi.org/10.1104/pp.108.125765

[24] Gui, J., Shen, J. and Li, L. (2011) Functional Characterization of Evolutionarily Divergent 4-Coumarate: Coenzyme A Ligase in Rice. Plant Physiology, 157, 574-586. https://doi.org/10.1104/pp.111.178301

[25] Lee, D., Meyer, K., Chapple, C. and Douglas, C.J. (1997) Antisense Suppression of 4-Coumarate: Coenzyme A Ligase Activity in Arabidopsis Leads to Altered Lignin Subunit Composition. The Plant Cell, 9, 1985-1998. https://doi.org/10.1105/tpc.9.11.1985

[26] Hu, W.J., Harding, S.A., Lung, J., Popko, J.L., Ralph, J., Stokke, D.D., Tsai, C.J. and Chiang, V.L. (1999) Repression of Lignin Biosynthesis Promotes Cellulose Accumulation and Growth in Transgenictrees. Nature Biotechnology, 17, 808-812. https://doi.org/10.1038/11758

[27] Sluiter, A., Hames, B., Ruiz, R., Scarlata, C., Templeton, D. and Crocker, D. (2012) Determination of Structural Carbonhydrates and Lignin in Biomass. NREL.

[28] Berry, P.M. (2004) Designing Lodging-Proof Wheat. Aspects of Applied Biology, 72, 177-184.

[29] Stapper, M. and Fischer, R.A. (1990) Genotype, Sowing Date and Plant Spacing Influence on High-Yielding Irrigated Wheat in Southern New South Wales. II. Growth, Yield and Nitrogen Use. Australian Journal of Agricultural Research, 41, 1021-1041. https://doi.org/10.1071/AR9901021

[30] Fischer, R.A. and Stapper, M. (1987) Lodging Effects on Highyielding Crops of Irrigated Semidwarf Wheat. Field Crops Research, 17, 245-258.

https://doi.org/10.1016/0378-4290(87)90038-4

[31] Jedel, P.E. and Helm, J.H. (1991) Lodging Effects on a Semidwarf and Two Standard Barley Cultivars. Agronomy Journal, 83, 158-161. https://doi.org/10.2134/agronj1991.00021962008300010036x

[32] Laude, H.H. and Pauli, A.W. (1956) Influence of Lodging on Yield and Other Cha- 
racters in Winter Wheat. Agronomy Journal, 48, 452-455.

https://doi.org/10.2134/agronj1956.00021962004800100005x

[33] Weibel, R.O. and Pendleton, J.W. (1964) Effect of Artificial Lodging on Winter Wheat Grain Yield and Quality. Agronomy Journal, 56, 487-488. https://doi.org/10.2134/agronj1964.00021962005600050013x

[34] Briggs, K.G. (1990) Studies of Recovery from Artificially Induced Lodging in Several Six-Row Barley Cultivars. Canadian Journal of Plant Science, 70, 173-181. https://doi.org/10.4141/cjps90-019

[35] Pinthus, M.J. (1973) Lodging in Wheat, Barley, and Oats: The Phenomenon, Its Causes, and Preventative Measures. Advances in Agronomy, 25, 210-256.

[36] Stapper, M. and Fischer, R.A. (1990) Genotype, Sowing Date and Plant Spacing Influence on High-Yielding Irrigated Wheat in Southern New South Wales. II Growth, Yield and Nitrogen Use. Australian Journal of Agricultural Research, 41, 1021-1041. https://doi.org/10.1071/AR9901021

[37] Easson, D.L., White, E.M. and Pickles, S.L. (1993) The Effects of Weather, Seed Rate and Cultivar on Lodging and Yield in Winter Wheat. The Journal of Agricultural Science, 121, 145-156. https://doi.org/10.1017/S0021859600077005

[38] Ishimaru, K., Togawa, E., Ookawa, T., Kashiwagi, T., Madoka, Y. and Hirotsu, N. (2008) New Target for Rice Lodging Resistance and Its Effect in a Typhoon. Planta, 227, 601-609. https://doi.org/10.1007/s00425-007-0642-8

[39] Mulder, E.G. (1954) Effect of Mineral Nutrition on Lodging of Cereals. Plant Soil, 5, 246-306. https://doi.org/10.1007/BF01395900 